\title{
Newborn interneurons in the accessory olfactory bulb promote mate recognition in female mice
}

\section{Livio Oboti ${ }^{1 \dagger}$, Roberta Schellino ${ }^{1}$, Claudio Giachino ${ }^{2}$, Pablo Chamero ${ }^{3}$, Martina Pyrski ${ }^{3}$, Trese Leinders-Zufall ${ }^{3}$, Frank Zufall ${ }^{3}$, Aldo Fasolo ${ }^{1}$ and Paolo Peretto ${ }^{1,4} *$}

${ }^{1}$ Department of Animal and Human Biology, University of Turin, Turin, Italy

2 Department of Molecular Embryology, Max Planck Institute of Immunobiology, Freiburg, Germany

${ }^{3}$ Department of Physiology, University of Saarland School of Medicine, Homburg, Germany

${ }^{4}$ Scientific Institute Cavalieri-Ottolenghi (NICO), Torino, Italy

Edited by:

Angelique Bordey, Yale University

School of Medicine, USA

Reviewed by:

Umberto Di Porzio, Genetics and Biophysics Adriano Buzzati Traverso, Italy

Armen Saghatelyan, Université Laval, Canada

Jean-Claude Platel, University Joseph Fourrier, France

*Correspondence:

Paolo Peretto, Scientific Institute Cavalieri-Ottolenghi (NICO), Regione

Gonzole, 10, 10043 Orbassano,

Torino, Italy.

e-mail:paolo.peretto@unito.it

\section{${ }^{\dagger}$ Present address:}

Livio Oboti, Department of

Physiology, University of Saarland

School of Medicine, 66421 Homburg,

Germany,

e-mail:l.oboti@mx.uni-saarland.de
In the olfactory bulb of adult rodents, local interneurons are constantly replaced by immature precursors derived from the subventricular zone. Whether any olfactory sensory process specifically relies on this cell renewal remains largely unclear. By using the well known model of mating-induced imprinting to avoid pregnancy block, which requires accessory olfactory bulb (AOB) function, we demonstrate that this olfactory memory formation critically depends on the presence of newborn granule neurons in this brain region. We show that, in adult female mice, exposure to the male urine compounds involved in mate recognition increases the number of new granule cells surviving in the AOB. This process is modulated by male signals sensed through the vomeronasal organ and, in turn, changes the activity of the downstream amygdaloid and hypothalamic nuclei involved in the pregnancy block response. Chemical depletion of newly generated bulbar interneurons causes strong impairment in mate recognition, thus resulting in a high pregnancy failure rate to familiar mating male odors. Taken together, our results indicate that adult neurogenesis is essential for specific brain functions such as persistent odor learning and mate recognition.

Keywords: pregnancy block, neurogenesis, male pheromones, Trpc2, AOB, medial amygdala, olfactory imprinting, Ara-C

\section{INTRODUCTION}

Interneurons at the first level of olfactory processing, the main olfactory bulb (MOB), are subjected to life-long replacement (Alvarez-Buylla and Garcia-Verdugo, 2002; Petreanu and AlvarezBuylla, 2002; Gheusi et al., 2009). The integration and survival of these cells depends on olfactory activity (Petreanu and AlvarezBuylla, 2002; Yamaguchi and Mori, 2005) and on their high excitability (Lin et al., 2010). In the MOB neurogenesis has been shown to be important for olfactory perceptual learning and longterm memory (Lazarini et al., 2009; Moreno et al., 2009) as well as social odor discrimination in mice (Sakamoto et al., 2011). We have previously shown that, similarly to the $\mathrm{MOB}$, inhibitory granule cells in the accessory olfactory bulb (AOB) are constantly replaced by immature neuronal precursors migrating from the subventricular zone (SVZ; Oboti et al., 2009). In female mice the number of the surviving cells is increased by exposure to bedding soiled by male urine (Oboti et al., 2009). Exposure to male urine odors can also facilitate estrous in females, leading to altered pubertyonset, shortened estrous cycle length, and interruption of embryo implantation soon after mating, an effect that is known as selective pregnancy block or Bruce-effect (Bruce, 1966). These neuroendocrine responses are mediated by vomeronasal (VN) excitatory projections to the medial amygdala $(\mathrm{MeA})$, the bed nucleus of the stria terminalis (BNST), the medial hypothalamus (MPA), and ultimately the dopaminergic neurons of the arcuate nucleus $(\operatorname{arc})$ that control prolactin release by the anterior pituitary (Li et al., 1989). During mating, the granule cell inhibitory modulation of the contextual male chemosignals is enhanced so that they are no more capable of estrous induction (Brennan et al., 1990; Matsuoka et al., 1997). This male-specific pheromone recognition process involves a restricted pool of granule cells in the $\mathrm{AOB}$, which inhibits mitral cell signal transmission to the forebrain areas involved in estrous regulation for several weeks (50-60 days; Brennan et al., 1990; Matsuoka et al., 1997). Long-term maintenance of this inhibition implies that, since matings may occur at shorter intervals, different or partially overlapping cohorts of cells may be necessary to each imprinting process. Here, we hypothesize that the sensorydriven granule cell addition in the $\mathrm{AOB}$ may provide the substrate for the pheromonal imprinting on stud male odors in order to avoid pregnancy block.

To sustain this idea, we show that adult neurogenesis in the $\mathrm{AOB}$ of female mice is regulated by vomeronasal inputs involved in mate pheromonal imprinting: it is enhanced by exposure to male pheromones comprised in the low molecular weight (LMW) fraction of male urine, the same compounds that are critical for mate recognition (Peele et al., 2003; Leinders-Zufall et al., 2004); it is triggered by MeA feedback sensory activity, and in turn attenuates the responses to male odors of the AOB-MeA 
downstream pathway which regulates estrous induction. In addition we show that this response is individual-specific since AOB young granule cells are prominently activated by those male signals driving their integration.

Ultimately, we show that long-term ablation of these cells, and re-exposure of recently mated females to their stud male, leads to embryo implantation failure, like when unfamiliar pheromones are sensed. Together, our results indicate that the pheromonal imprinting process required to block estrous induction by mating male pheromones is preferentially localized on AOB newborn granule cells.

\section{MATERIALS AND METHODS ANIMALS}

Experiments employed three strains of mice: CD-1 [females, ages: postnatal day (p) 20 or 45; males, ages: 4-6 weeks], c57bl6/j (females, age: $\mathrm{p} 45$ ), and $\operatorname{trpc} 2^{-1-}$ (females, age: $\left.\mathrm{p} 45\right)$. In all experiments CD-1 strain female (or male) mice have been used, the c57bl6/j strain has been used only in the trpc2-ko experiment. Animals of the same gender were maintained 4-6 per cage in rooms with a 12:12 light/dark cycle, with standard diet and water ad libitum. All female subjects were kept in isolation for the duration of all experiments. All procedures were in accordance with the European Communities Council Directive of November 24, 1986 (86/609/EEC) and with institutional guidelines on animal welfare (DL 116/92) of the University of Turin and the University of Saarland. Experiments were designed to minimize the number of animals used.

\section{BrdU TREATMENTS}

To identify newly generated cells at different survival times, mice were intraperitoneally injected with bromodeoxyuridine (BrdU) in $0.1 \mathrm{M}$ Tris ( $\mathrm{pH} 7.4$ ) twice a day (delay $=8 \mathrm{~h}, 100 \mathrm{mg} / \mathrm{kg}$ body weight), and sacrificed 28 days later for evaluation of neuronal survival.

\section{IMMUNOHISTOCHEMISTRY}

Following anesthesia, mice were transcardially perfused with phosphate-buffered saline (PBS) followed by $4 \% \quad(\mathrm{w} / \mathrm{v})$ paraformaldehyde in PBS. Brain tissue was dissected, incubated overnight in $30 \%$ sucrose in PBS at $4^{\circ} \mathrm{C}$, embedded in O.C.T (Tissue-Tek), and snap-frozen in a dry ice/2-methylbutane bath. $25-\mu \mathrm{m}$ thick floating sections were used in all immunohistochemical assays. Newborn cells in the olfactory bulb (OB) were labeled as described previously (Oboti et al., 2009). A glucose oxidase-diaminobenzidine (DAB) method was used for the c-Fos immunostaining. Briefly, tissue sections of the whole brain were first washed in phosphate-buffered saline (PBS) containing 7.5\% normal goat serum (NGS) and $0.1 \%$ Triton X-100 for $3 \mathrm{~h}$, followed by incubation in primary antibody prepared in blocking solution (2\% NGS and $0.1 \%$ Triton X-100 in $0.01 \mathrm{M} \mathrm{PBS,pH}$ 7.4). Sections were then incubated for $48 \mathrm{~h}$ at $4^{\circ} \mathrm{C}$ in primary rabbit antibody against c-Fos (1:5000; rabbit monoclonal IgG, Santa Cruz Biotechnologies, CA, USA). Secondary antibody was biotinylated goat anti-rabbit IgG (1:250; Vector Laboratories, Burlingame, CA, USA) in blocking solution. Endogenous peroxidase was inactivated by incubation with $3 \% \mathrm{H} 2 \mathrm{O} 2$ for $30 \mathrm{~min}$ followed by incubation with avidin-biotin-peroxidase (HRP) complex
(1:150; Vector Laboratories, Burlingame, CA, USA). Immunoreactivity was visualized using $0.05 \mathrm{M}$ Tris- $\mathrm{HCl}$ containing 3,3'diaminobenzidine tetrahydrochloride (DAB, $1.5 \mathrm{mg} / \mathrm{ml}$; Sigma, Italy) for $5 \mathrm{~min}$. Sections were incubated in the same DAB solution containing $0.45 \mu \mathrm{l} / \mathrm{ml} \mathrm{H}_{2} \mathrm{O}_{2}$ and $0.3 \% \mathrm{NiCl}$. Sections were then dehydrated and coverslipped with Sintex (Nuova Chimica, Cinisello Balsamo, Italy).

Single labeling for BrdU and double labeling for doublecortin and BrdU (DCX/BrdU), c-Fos/BrdU, and c-Fos/NeuN have been described previously (Oboti et al., 2009). For double labeling BrdU and DCX or, olfactory marker protein (BrdU/OMP) tissue slices have been incubated in anti-DCX or anti-OMP primary antibody (DCX: 1:500; goat polyclonal IgG; SantaCruz Biotechnologies, CA, USA; OMP: 1:6000; goat polyclonal IgG; kindly provided by F.L. Margolis) in PBS containing 1\% normal donkey serum (NDS) and $0.5 \%$ Triton X-100 for $24 \mathrm{~h}$, followed by an anti-goat secondary antibody (1:250; Vector Laboratories, Burlingame, CA, USA) in PBS 0.01 M. Fluorescent staining has been obtained with avidinFITC (1:400; Vector Laboratories, Burlingame, CA, USA) for $1 \mathrm{~h}$. Followed 30' HCL 2N incubation for BrdU antigen-retrieval, incubation with primary anti-BrdU antibody (1:8000, rat monoclonal IgG, Oxford Biotechnologies). In all protocols described three rinses (10 min each) in $0.01 \mathrm{M}$ PBS have been performed between any incubation.

\section{CELL COUNTING AND STATISTICAL ANALYSIS}

Analysis of the number and density of BrdU-positive nuclei in the $\mathrm{AOB}$ and $\mathrm{MOB}$ granule cell layer $(\mathrm{GrL})$, as well as the percentage of double labeled c-Fos-positive cells (BrdU), was performed as described previously (Oboti et al., 2009) using blind quantification. For each AOB, 9-10 tissue sections (each $25 \mu \mathrm{m}$ thick) were used in each analysis and densities were calculated by summing cell counts made on all sections per animal and referred to the proper cellular layer volume ( $\Sigma$ of sampled areas $\left.\mu \mathrm{m}^{2} \times 25 \mu \mathrm{m}\right)$. Newborn cells were sampled in the MOB GrL on five $25-\mu \mathrm{m}$ thick tissue sections per animal using a fixed sampling volume $\left(1000 \times 400 \times 25=10,000,000 \mu \mathrm{m}^{3}\right)$ that was positioned below the $\mathrm{AOB}$, symmetrically with reference to the rostral migratory stream axis (Figure 1A). In all cases the sampled volume was located in the ventral-medial $\mathrm{MOB}$, a region that is strongly activated by social odors and urine detected via the main olfactory epithelium (MOE; Xu et al., 2005). Double labeled c-Fos/BrdU cells were visualized and counted with a confocal microscope using a UPlanFL $100 \times$ (n.a. 1.3) Olympus objective. Quantification of c-Fos-positive nuclei in the MeA and MPA was performed using automated routines (ImageJ), applying a fixed threshold to the images and using the particle-counting plug-in.

Images of the anterior MeA and MPA were captured in anatomically matched brain sections (three per region for each animal). Particle number ( $n^{\circ}$ of labeled nuclei) revealed after threshold selection was counted in a standard circular sampling area (radius $=75 \mu \mathrm{m}$ ) and was then divided by the volume of tissue analyzed $\left(\pi \times 75^{2} \times 25 \mu \mathrm{m}^{3}\right)$. All c-Fos analysis data (BNST, MeA, MPA, arc) have been eventually normalized to the respective control values in each group (Figure 2). The amount of NeuN-positive nuclei after Ara-C or Saline treatment has been evaluated in the AOB granular layer on three tissue sections per animal (three animals per group) applying a grid over the 

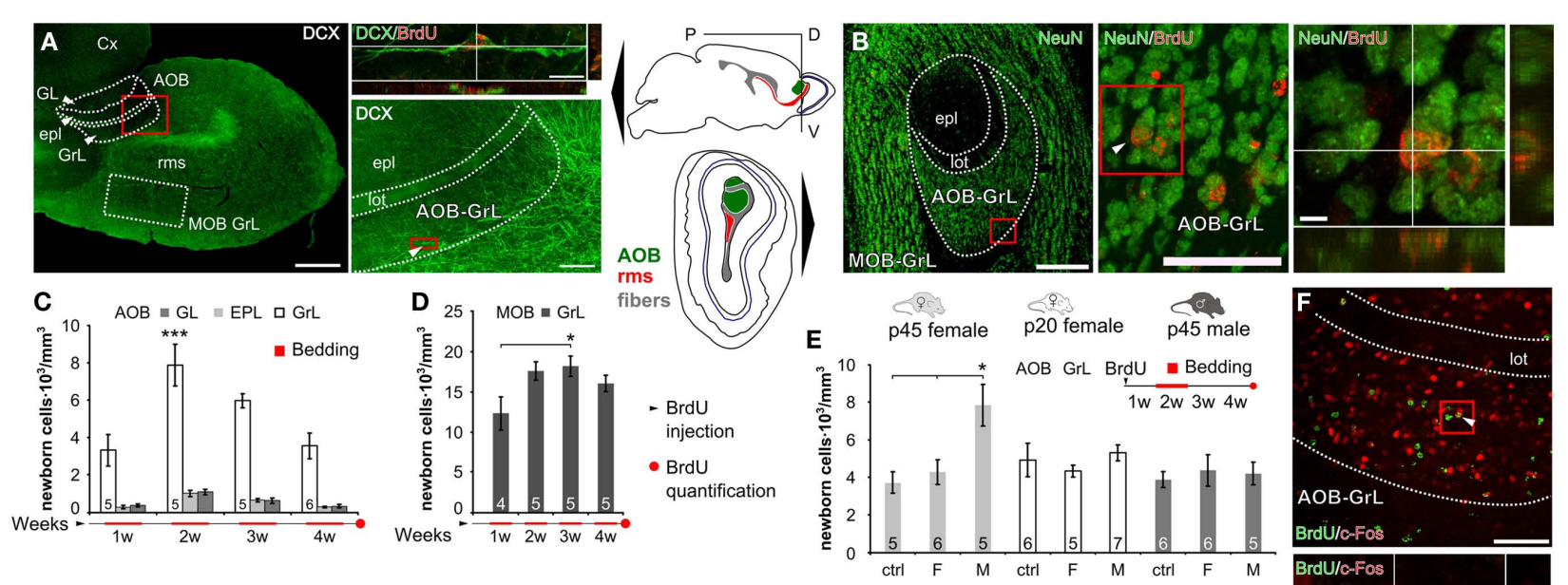

G
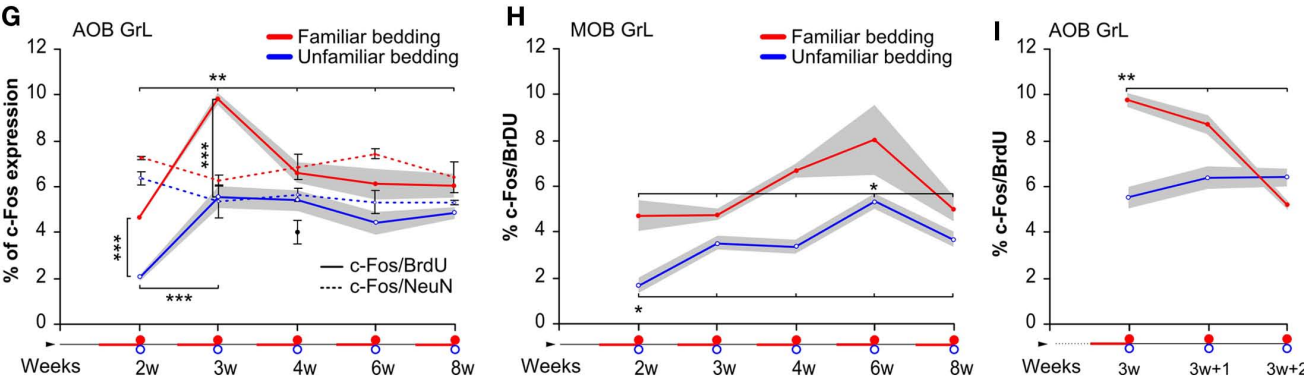
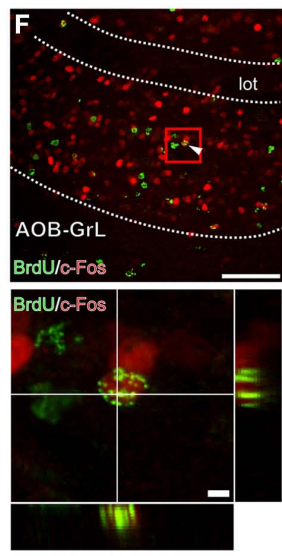

- BrdU injection

-/o c-Fos/BrdU \%

quantification
FIGURE 1 | Male pheromones affect neuronal survival in the adult female AOB. (A) Olfactory bulb sagittal section showing doublecortin (DCX)

immunostaining in the $\mathrm{OB}$ and throughout the rostral migratory stream (rms). Enlargement (upper right) shows a BrdU/DCX double-stained cell located in the AOB-GrL 10 d.p.i. ( $x: y: z=1: 1: 8)$. Dotted white lines indicate the sampled areas in each tissue section: glomerular $(G L)$, external plexiform (epl), granular (GrL) AOB layers and MOB granular layer. (B) Coronal OB section showing NeuN labeling in the MOB and AOB-GrL. Examples of BrdU/NeuN co-labeled cells are shown at higher magnification (see arrowhead, 15 d.p.i.,

$x: y: z=1: 1: 4)$. In (A) and (B) red boxed areas are depicted at higher magnification in the right panels. (C,D) Quantification of BrdU-labeled cells at 28 d.p.i. (see red circle in the bar below the graphs) in multiple AOB layers and MOB GrL of p45 female mice after familiarization performed in four different weeks (red bars below the graphs). (E) Density of newborn granule cells in adult females, pre-pubertal females, and adult males evaluated at 28 d.p.i. of BrdU and after 1 week exposure to female (F) or male (M) bedding (from 7th to 14th d.p.i. of BrdU). (F) Example of a sagittal AOB section showing c-Fos/BrdU double immunolabeling in the $\mathrm{GrL}$, with a co-labeled cell in the magnified panel $(x: y: z=1: 1: 4)$. (G,H) Percentage of c-Fos/BrdU and c-Fos/NeuN -positive cells induced by familiar and unfamiliar pheromones in AOB-GrL (G) and c-Fos/BrdU in MOB GrL (H). In (G) the black dot represents the basal levels of c-Fos expression in 4 weeks old $A O B$ granule cells. (I) Retention time of newborn AOB granule cell preferential activity. Data are means \pm SEM [represented by gray areas in $(\mathbf{F}-\mathbf{H})$ ], the numbers in the graph bars indicate the amount of animals used. ${ }^{*} P<0.05$, ${ }^{*} P<0.01$, ${ }^{*}{ }^{*} P<0.001$ (Table 1). Bars in (A): left $500 \mu \mathrm{m}$, right $100 \mu \mathrm{m}$, upper right $5 \mu \mathrm{m}$. In (B): left $200 \mu \mathrm{m}$, middle $50 \mu \mathrm{m}$, right $5 \mu \mathrm{m}$. In (F): upper $100 \mu \mathrm{m}$ lower $5 \mu \mathrm{m}$. section (3D grid modular size $40 \mu \mathrm{m}^{2} \times 25 \mu \mathrm{m}$ ) and counting NeuN-positive nuclei in 1/5 grid modules (Neurolucida setup with a Nikon Plan Fluor $40 \times / 0.75$ objective has been used; only infocus nuclei have been counted, excluding those crossing the upper and right sides of each module) and referring the estimated total $\left(n^{\circ}\right.$ nuclei $\left.\times 5\right)$ to the sampled volume (sampled area $\times$ section thickness). When normally distributed, data have been analyzed for variance differences with a univariate general linear model (F-test) using the cell densities as dependent variables and treatment, age, cell type, cell age, pheromone as between-subject factors. The type one error ( $\alpha$ value) under which the $F$-test has been accepted as statistically significant has been set to 0.05 . In each Anova/Glm F-test the Tukey-HSD post hoc comparison was performed in case of significance $(P<0.05) . t$-Tests have been used in simple 1:1 comparison (one dependent variable, one grouping variable with two levels). Whenever parametric tests have been used, data represented in the histograms are mean values \pm the SEM. Non-parametric tests (Wilcoxon and Chi-square tests) have been used to assess differences in either the proportion of time spent exploring odorant sources in the olfactory behavioral tests or the percentage of successful pregnancies, respectively. In the evaluation of the pregnancy rate in the different conditions analyzed, the expected values have been estimated using the pregnancy rates of first treated groups in the comparisons detailed in Table 1: saline-treated (1), Ara-C-mate exposure (2), Ara-C-short-term (4), saline-vnx (5). Whenever a data set has been used more than one time for any comparison (for example in the comparison of the percentages of pregnancy rate) the $\alpha$ value has been halved as many times as the quantity of comparisons performed. For a complete list of the results of the statistical analyses performed refer to Table 1.

\section{CHEMOSENSORY STIMULATION}

The animals exposed to male/female soiled bedding in the different experiments were given a daily renewed bedding mixture collected from the cage of an individually housed male or 


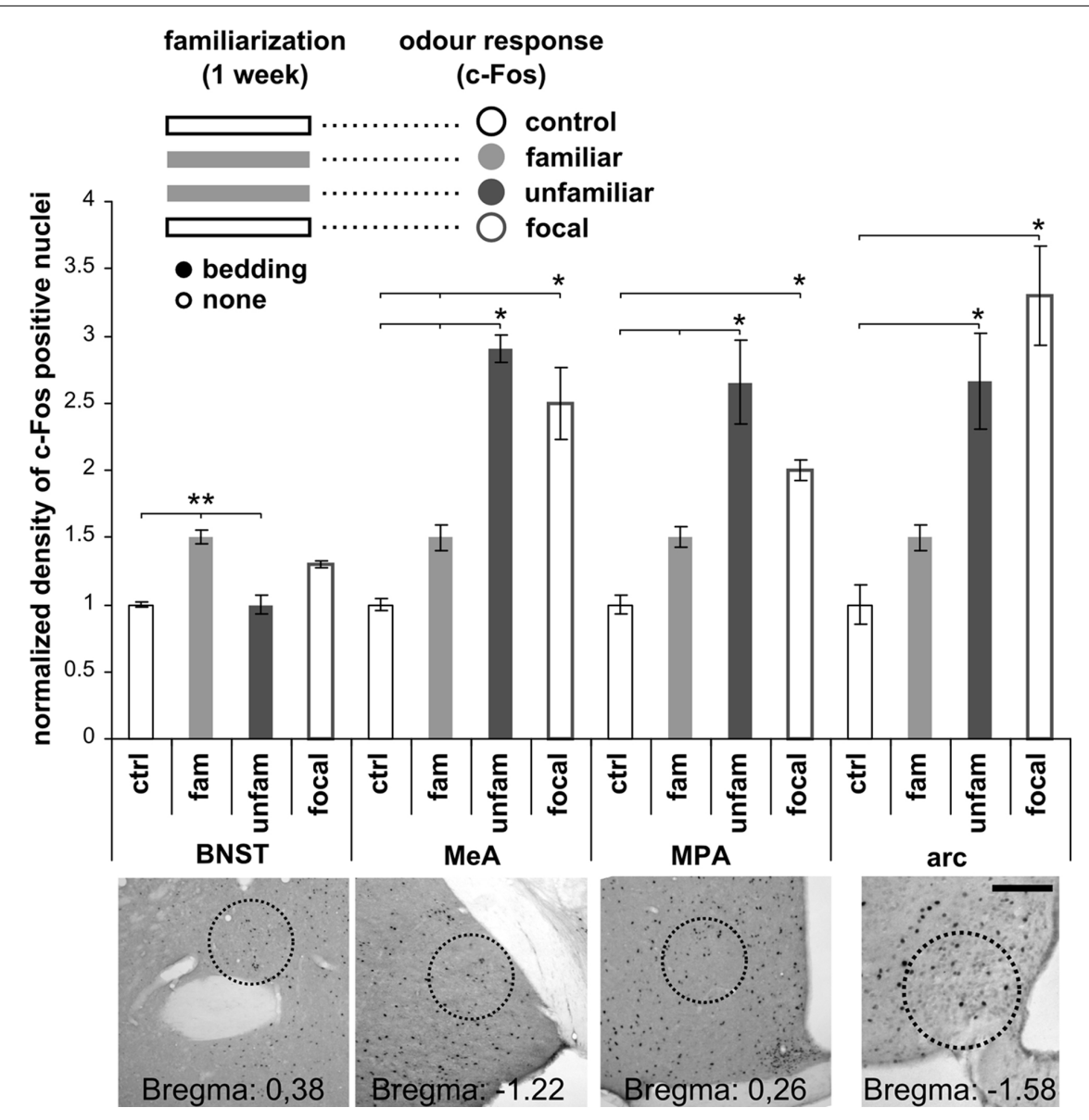

FIGURE 2 | Familiar male odors induce attenuated responses in the vomeronasal system. Normalized c-Fos expression density levels evaluated in the VNS after male bedding exposures. IEG expression has been evaluated in the BNST, MPA, MeA, and arc after familiarization (1 week exposure, light-gray bar in the upper scheme) to male individual odors and re-exposure to the stimuli produced by the same donor (familiar, light-gray) or by another male (unfamiliar, dark-gray). Another group of females has been exposed to male individual odors with no prior experience of male derived stimuli (focal, lined gray). As shown in the graph, novel odors (unfamiliar or focal) induce strong activity in the MeA, MPA, and arc, while familiar odors (light-gray) do not. Radius of sampled areas: $75 \mu \mathrm{m}$. Scale bar: $100 \mu \mathrm{m}$. Data are normalized means \pm SEM, ${ }^{*} P<0.05,{ }^{*} P<0.01$. female CD-1 mouse, respectively. In case of the $\operatorname{trpc} 2^{+/+}$and $\operatorname{trpc} 2^{-1-}$ female mice, soiled bedding of a c57bl6/j male mouse was used. Familiarization with male bedding consisted of a 7-dayslong exposure to soiled bedding material, renewed each day. The "control" groups were treated similarly but with clean bedding. For the c-Fos expression analyses, all groups including controls underwent a 30-min soiled bedding presentation, $90 \mathrm{~min}$ before perfusion, to detect odor specific c-Fos activation. For stimuli consisting of urine or urine fractions, $100 \mu \mathrm{l}$ of each solution was added to filter paper which was submitted into the cage of the females twice a day (the stimulation has been repeated to avoid inefficiency due to paper consumption by the animals). Urine fractionation (Chamero et al., 2007), protease treatment (Chamero et al., 2007), and menadion displacement of volatile compounds from major urinary proteins (MUPs; Xia et al., 2006) were performed as previously described.

\section{STEREOTAXIC SURGERIES}

Osmotic mini-pump installation has been performed (p40 CD-1 females) as described previously (Morgan et al., 1987) using the coordinates (referring to Bregma): anterior-posterior, $0.40 \mathrm{~mm}$; medial-lateral, $0.7 \mathrm{~mm}$; and dorsal-ventral, $3 \mathrm{~mm}$. To assess the efficiency of the anti-mitotic administration, BrdU injections have been used in order to label proliferating cells during the treatment (after 14 days in the 28-days long-term protocol or 4 days in the 7-days short-term protocol, not shown). After each anti-mitotic infusion ( 28 or 7 days), the expression of BrdU in the OB was inspected and animal specimens showing even a scarce presence of BrdU-positive nuclei were discarded.

For the amygdala lesions, mice (p38 CD-1 females) were anesthetized with a ketamine ( $4 \mathrm{mg} / \mathrm{kg}$ body weight $)$-xylazine $(1 \mathrm{mg} / \mathrm{kg}$ body weight) solution and placed on a stereotaxic apparatus (Kopf Instrument). Lesions were performed by injecting ibotenic acid (IB; Sigma, Italy) diluted at $10 \mathrm{mg} / \mathrm{ml}$ in saline solution ( $\mathrm{pH} 7.4$ ) using a picospritzer III system (Science Products $\mathrm{GmbH}$, Hofheim, Germany) with a fine glass pipette (diameter $=40 \mu \mathrm{m})$. Lesions were performed into the medial nucleus of the amygdala (MeA) at the coordinates (referring to Bregma): anterior-posterior, $-1.2 \mathrm{~mm}$; medial-lateral, $2.1 \mathrm{~mm}$; and dorsal-ventral, $5.3 \mathrm{~mm}$. Sham-lesioned mice underwent the same surgical procedure with 
Table 1 | Results of all statistical analyses performed.

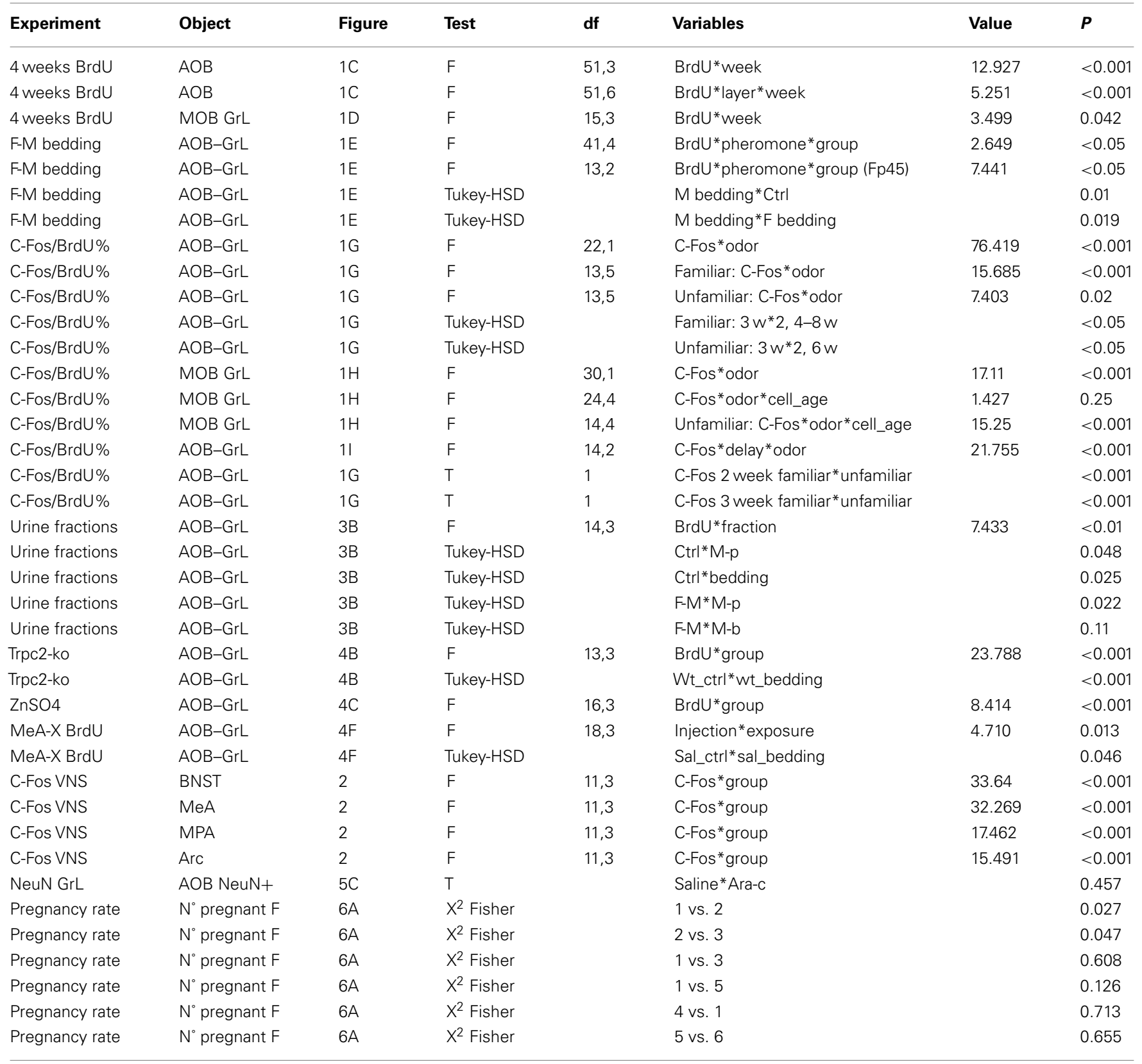

neurotoxic-free saline solution. All surgically operated mice were allowed to recover in their home cages in a separate room for at least 7 days before the beginning of the experiments. At the age of p45, mice were injected with BrdU (day 0) and exposed to male soiled bedding between day 7 th and 14th. Behavioral analysis has been performed at day 6th and 15th to assess the preference for male derived volatiles before and after the familiarization phase. At 28 days after BrdU injections, brains have been harvested to quantify BrdU-labeling in the OB.

For the surgical vomeronasal nerve cut, mice (p68 CD1 females) were anesthetized with a ketamine $(4 \mathrm{mg} / \mathrm{kg}$ body weight)-xylazine (1 mg/kg body weight) solution and placed on a stereotaxic apparatus (Kopf Instrument). A midline incision was made over the scalp and a hole was made on the skull with a drill (Bregma: anterior-posterior, $5 \mathrm{~mm}$; medial-lateral, $0 \mathrm{~mm}$; and dorsal-ventral, $4.1 \mathrm{~mm}$ ). A custom made steel blade having a width of $0.5 \mathrm{~mm}$ was introduced between the bulbs with a $+40^{\circ}$ slope referring to the vertical axis to cut the vomeronasal fibers. Occurrence of the lesion has been established by OMP immunohistochemistry 7-15 days after wound closure and recovery.

\section{OLFACTORY PREFERENCE TEST}

Preference for male derived volatiles before and after a 5days bedding exposure was assessed as described previously (Moncho-Bogani et al., 2005), but two sources of chemosensory 
stimulations were presented during each day: one was a direct exposure to male soiled bedding, while the other consisted in male bedding contained in a drilled box, to prevent direct physical contact with this second odor source. Olfactory preference tests were performed for male volatile odors derived from both odor sources: one considered experienced (when direct bedding exploration was allowed), the other considered unexperienced, (as no direct contact with male bedding did occur). A $90 \times 30 \times 30$ testing cage was used and the odor stimuli were placed at opposite sides (chosen randomly). Male odor stimuli were discharged when female mice showed higher/lower explorative responses toward one of the two, before the bedding exposure period. The duration of every nose poke on the odor source (box) and the proportion of total time (pT) spent exploring one odorant source (calculated as the time spent sniffing one odor/total time spent sniffing ratio) was calculated with a dedicated software [JWatcher; Copyright (c) 2000-2006 Daniel T. Blumstein, Janice C. Daniel, and Christopher S. Evans. All rights reserved].

\section{OLFACTORY DISCRIMINATION TASK}

The habituation-dishabituation to male derived urine volatiles was used to measure MOE-mediated olfactory discrimination following a previously described protocol (Breton-Provencher et al., 2009). Briefly, after $20 \mathrm{~min}$ habituation to the testing cage, mice were familiarized with a first odor (odor of habituation) in four successive sessions and then exposed once to a novel odor (odor of dishabituation). Each session was $1 \mathrm{~min}$ long and was followed by $10 \mathrm{~min}$ inter-session interval. Olfactory discrimination was analyzed using two different male odors delivered via patches of filter paper tainted with male urine and enclosed in a perforated plastic box. The two odors have been both tested alternatively as novel stimuli (during dishabituation) in separate sessions. Odor sources consisted of urine soaked filter papers contained in a drilled plastic box.

\section{BRUCE-EFFECT, PREGNANCY BLOCK TEST}

To evaluate the rates of pregnancy failure (Bruce-effect), a previously established protocol of matings and pheromonal stimulations was used (Peele et al., 2003; Leinders-Zufall et al., 2004). We have preliminarily assessed the pregnancy rate for our laboratory mice as close to $100 \%$ using 32 female mice, that were in the receptive pro-oestrus/oestrus stage, and mating them using the traditional schedule. Females were returned to their home cage $24 \mathrm{~h}$ after mating. At $12 \mathrm{~h}$ intervals (five times) each female was returned to her mating partner for $20 \mathrm{~min}$. In this way exposures to the mate covered 3 days after the beginning of the mating and were timed to coincide with the prolactin peaks occurring $1 \mathrm{~h}$ before lights-on and lights-off (Peele et al., 2003; Leinders-Zufall et al., 2004). One group of females was exposed to an unfamiliar male to evaluate the percentage of pregnancy loss (60\%). Eleven days after mating the females were killed and their uteri examined for implantation sites of the ova.

\section{RESULTS \\ NEWBORN AOB GRANULE CELLS IN FEMALE MICE ARE POSITIVELY SELECTED BY MALE ODORS}

The $\mathrm{AOB}$, as the $\mathrm{MOB}$, represents an integration site for doublecortin-positive (DCX) neuroblasts migrating from the adult SVZ, as revealed by BrdU birth dating experiments (Figure 1A; Oboti et al., 2009). When these cells reach the AOB cellular layers, they acquire a mature phenotype as indicated by BrdU/NeuN co-labeling, already evident 15 days after BrdU injection (Figure 1B). The survival of AOB newborn neurons in adult female mice has been shown to be enhanced by subsequent longterm exposure (28 days post injection of BrdU; d.p.i.) to male pheromones present in cage bedding, when direct vomeronasal contact is allowed (Oboti et al., 2009). However, by labeling newborn neurons with BrdU after 7 days of male bedding exposure, other authors reported that bulbar neurogenesis is increased afterward as an indirect proliferative effect of such sensory stimulation (Mak et al., 2007). Hence, it is currently unknown at which age the newborn granule cells begin to respond to sensory stimuli and when these neurons are integrated into functional adult $\mathrm{AOB}$ circuits. Moreover, the question whether these neurons support any specific sensory function dependent on vomeronasal sensing remained unanswered.

To address these points, we first analyzed the sensory-driven positive selection of newborn AOB granule cells labeled before exposure to male urine soiled bedding in adult females. This occurred in different moments of their maturation: 1st week (07th d.p.i.), 2nd week (8th-14th d.p.i.), 3rd week (15th-21st d.p.i.), and 4th week (22nd-28th d.p.i.; Figures 1C,D). We previously found that the migration of one BrdU-labeled pool of SVZ neuroblasts reaching the $\mathrm{AOB}$ is accomplished in the 1st week as its density reaches the maximum value at 7 d.p.i., while subsequently starts to decrease (Oboti et al., 2009). Here we show that, immediately after this peak (during the 2 nd week), familiarization with male soiled bedding is more effective in promoting cell survival, indicating that, from 7 to 14 days after their genesis, most of AOB newborn cells undergo sensory-driven positive selection (Figure 1C). This effect was more prominent in the GrL of the AOB (Figure 1C) and much weaker in the MOB GrL (Figure 1D). Remarkably, such an increase in BrdU-positive cells in the AOB occurred only in adult females after exposure to male derived pheromones, whereas exposure to cues from both genders was uneffective in both adult males and pre-pubertal females (Figure 1E).

It is known that sensory experience influences neuronal integration in the neurogenic areas increasing the number of new neurons functionally involved in the activated sensory circuits (Magavi et al., 2005; Kee et al., 2007). Given that mate pheromonal imprinting in mice requires a cellular substrate responding specifically to male individual odors in the AOB (Matsuoka et al., 1997), we asked whether AOB new granule cells could have such capability.

To answer this question, we combined immunostaining for c-Fos, a marker for neuronal excitation (Morgan et al., 1987; Kovacs, 2008), and BrdU labeling (Magavi et al., 2005; Kee et al., 2007; Figure 1F). We quantified the percentage of c-Fos/BrdU coexpression (the fraction of BrdU-positive cells expressing cFos) induced by familiar (experienced for 1 week) or unfamiliar (never experienced before) male soiled bedding, at different times after granule cell genesis in the $\mathrm{AOB}$ and $\mathrm{MOB}$ GrL of female mice (Figures 1G,H). We found that newborn AOB granule cells preferentially responded to experienced male individual cues around the age of 3 weeks after BrdU labeling (Figure 1G). 
Moreover, this response was transient and vanished within 1 week following bedding exposure (Figure 1I). This age-specific granule cell involvement in $\mathrm{AOB}$ sensory processing was not evident while considering the total granule cell population (including pre-existing NeuN-positive neurons; Figure 1G, dotted lines) or granule cells aged over 3 weeks (at 28 days). Indeed, c-Fos expression levels in older cells (BrdU-positive) were not significantly increased by bedding exposure and were comparable both to control conditions (black dot in Figure 1G) or to those of NeuN-positive granule cells ( $4 \mathrm{w}$-bedding, $6.6 \pm 0.4 \%$; ctrl, $5.14 \pm 0.59 \%, P=0.21 ; 4 \mathrm{w}-\mathrm{NeuN}, 5.27 \pm 0.47 \%$; $4 \mathrm{w}$-ctrl, $5.14 \pm 0.59 \%, P=0.9$; means \pm SEM). Moreover, although $\mathrm{c}$-Fos expression levels in $\mathrm{MOB}$ newborn granule neurons were higher after exposure to familiar chemostimuli in comparison to unfamiliar ones, the peak activity occurred at a much later time point (i.e., around 6 weeks, Figure $\mathbf{1 H}$ ) indicating that the preferential involvement of $\mathrm{MOB}$ newborn interneurons in processing these odors persists for longer times and spans different cell ages (Magavi et al., 2005).

Together, these results indicate that, in female mice, the integration of $\mathrm{AOB}$ newborn granule cells is sensitive to male individual chemosignals during the $2 \mathrm{nd} / 3 \mathrm{rd}$ week of cell age and occurs preferentially in the same circuits that respond to these chemosignals.

The transient nature of this effect confirms the preferential involvement in the elaboration of vomeronasal signals of AOB interneurons in this cell age. Therefore, given the relevant role of granule interneurons in gating bulbar output activity (Halem et al., 2001; Matsuoka et al., 2004; Breton-Provencher et al., 2009), AOB young granule cells are likely to convey important individual odor informations to brain centers related to estrous induction. Accordingly, after 1 week familiarization, we found that re-exposure to the same male odor stimuli (familiar), but not to novel ones, induced attenuated responses in the downstream nuclei of the vomeronasal pathway controlling estrous induction. To rule out a possible effect of odor familiarization on the extent of this response, we stimulated female mice with novel odors with or without previous contact with the familiar ones (unfamiliar or focal stimulation, respectively). As a consequence of familiar odor exposure at the end of the familiarization period, increased c-Fos expression levels have been observed in the BNST (Figure 2). This is consistent with a role of this brain region in mediating olfactory responses related to experienced stimuli (Hosokawa and Chiba, 2007). Conversely, familiar odors elicited attenuated responses the MPA, MeA, and arc (Figure 2). These results suggest that the enhanced response shown by newly generated AOB neurons to male individual odors could be linked to the activity induced by the same cues in amygdaloid and hypothalamic nuclei, both of which are known to be involved in estrous induction and thus in the pregnancy block response.

\section{AOB NEUROGENESIS IS AFFECTED BY PHEROMONES IN THE LMW FRACTION OF MALE URINE}

Individual odor signatures in scent marks are encoded by chemicals excreted with urine (Brennan and Zufall, 2006). We therefore tested the effect of male urine alone (M-U; Figure 3A) and found that it promoted AOB granule cell integration as well as soiled
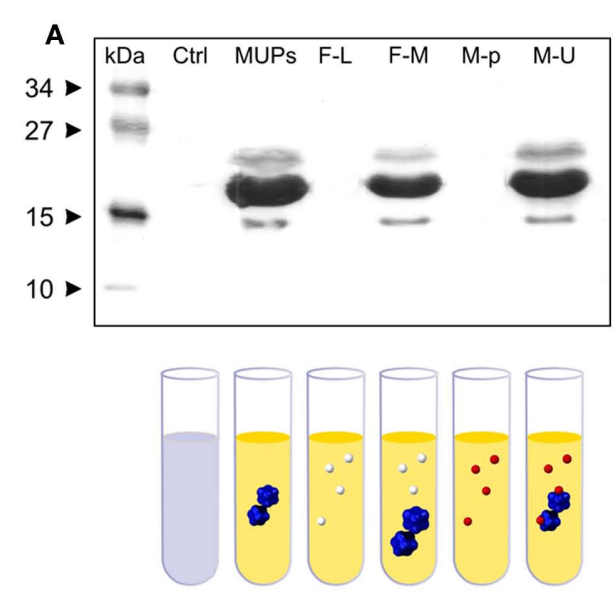

Ctrl MUPs F-L F-M M-p M-U
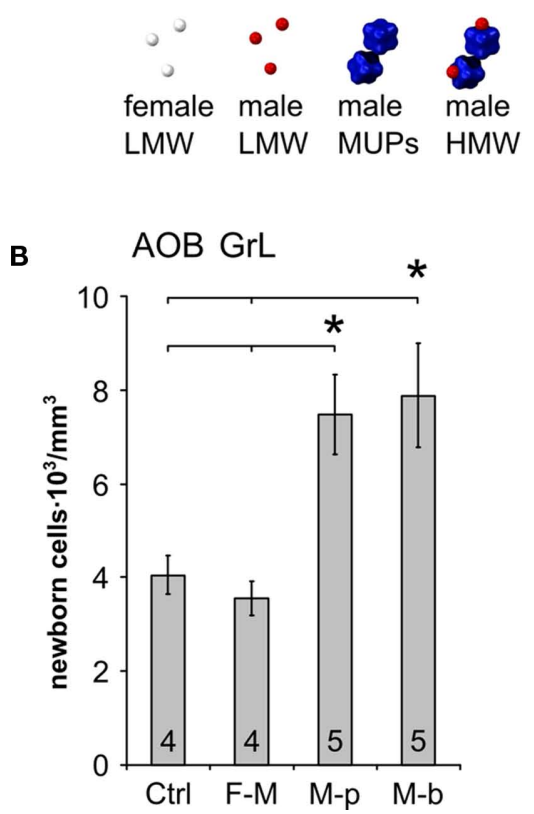

FIGURE 3 | Male urine LMW pheromones increase AOB granule cell survival. (A) Strategy for isolating different urine fractions. Protein gel electrophoresis showing the protein content in each fraction (MUPs: male HMW urine fraction containing MUPs treated with menadion, F-L: female LMW fraction used as diluting solution for male MUPS, F-M: female urine LMW fraction loaded with male MUPs, M-p: male urine treated with proteases, M-U: male urine). Proteins (>10 kD) are present only in those fractions of male urine that contain MUPs. HMW proteins are absent in female LMW urine fraction or male urine after protease treatment. (B) Densities of 28 days old BrdU-positive cells in the AOB-GrL after exposure to different fractions of male urine or male soiled bedding (M-b) during the 2nd week after injection. Means $\pm S E M$, number in each bar indicates the amount of animals used, ${ }^{*} P<0.05,{ }^{*} P<0.01$.

bedding exposure (urine, $7398.5 \pm 742.2$ nuclei $/ \mathrm{mm}^{3}, n=8$; ctrl, $3739.8 \pm 609.9$ nuclei $/ \mathrm{mm}^{3}, n=5 ; P=0.0029 ;$ means $\left.\pm \mathrm{SEM}\right)$. To gain further insight into the nature of the cues affecting $\mathrm{AOB}$ neurogenesis, we employed distinct male urine fractions and analyzed the density of BrdU-positive cells 28 days after injection (Figures 3A,B). These cues could include molecules present in 
the LMW fraction (containing small organic molecules and small peptides) as well as high molecular weight MUPs (contained in the HMW fraction; Brennan and Zufall, 2006). We found that the M-p fraction of urine, in which all MUPs were degraded by protease treatment (Figure 3A), was still capable of increasing granule cell survival to levels comparable to those seen after exposure to male soiled bedding (M-b, Figure 3B). Consistent with this result, the HMW fraction of male urine treated with menadion to deprive it from all volatile ligands (Chamero et al., 2007) and loaded onto female LMW urine fraction (F-M), was uneffective (Figure 3B). These findings were specific for the $\mathrm{AOB}$, as neither male urine (M-U) nor any of the urine fractions affected MOB GrL neuronal survival (urine, $15939.3 \pm 1566.9$ nuclei $/ \mathrm{mm}^{3}, n=8$; ctrl, $16949.7 \pm 1295.7$ nuclei $/ \mathrm{mm}^{3}, n=5 ; P=0.632$; means \pm SEM). Together, these results rule out an essential role for MUPs in increasing AOB neuronal survival and indicate that all activity is comprised in the LMW fraction of male urine which is primarily important for mate recognition (Peele et al., 2003; Leinders-Zufall et al., 2004).

\section{MALE ODORS INCREASE AOB GRANULE CELLS THROUGH BOTH PERIPHERAL AND CENTRAL INPUTS}

We have previously observed enhancement of neuronal survival in the AOB of adult female mice only if direct contact with male soiled bedding was allowed (Oboti et al., 2009), suggesting a necessary role of VNO sensory inputs. It has been proposed that experiencedependent circuital remodeling in peripheral sensory areas, when triggered by feedback activity from higher order cortical relays, can be functionally related to sensory perception (Gilbert and Sigman, 2007). Similarly, neuronal activity in the AOB can be regulated by centrifugal inputs from the $\mathrm{MeA}$, as a result of inputs converging from both the main and accessory olfactory systems (Pankevich et al., 2006; Martel and Baum, 2009). Thus, cellular activation of the AOB could be generated either by peripheral or central inputs or both (Pankevich et al., 2006).

To distinguish between these possibilities, we first compared the effects of genetic deletion of the Trpc 2 cation channel (leading to impaired VN function; Leypold et al., 2002) with lesions of the MOE caused by intranasal irrigation of zinc-sulfate $\left(\mathrm{ZnSO}_{4}\right.$, see the functional ablation sites in Figure 4A; McBride et al., 2003). Adult female mice were exposed to male bedding on days 7 th14 th after BrdU treatment when the effects of the sensory input on survival of AOB newborn neurons are maximal. Enhanced AOB granule cell survival after male bedding exposure was absent in $\operatorname{trpc} 2^{-1-}$ mice (Figure 4B, newborn MOB granule cells were unaffected in both $\operatorname{trp} c 2^{-1-}$ and $\operatorname{trp} c 2^{+/+}$mice, data not shown). By contrast, $\mathrm{ZnSO}_{4}$ lesions of the MOE (assessed by the lack of OMP staining in the MOB glomerular layer) did not abolish the enhanced neuronal survival in the AOB (Figures 4C,D). Thus, vomeronasal contact is necessary and sufficient to increase new AOB granule cells.

Next, to address the role of centrifugal inputs, we delivered excitotoxic lesions to the MeA by injections of ibotenic acid (IB, Figures 4A,E; Chauveau et al., 2008), a glutamatergic agonist, and stimulated both lesioned and sham-lesioned (saline injected) mice with male bedding from the 7 th to the 14th d.p.i. (BrdU). We assessed the efficiency of the lesions using both immunohistochemical (i.e., absence of the neuronal marker NeuN in regions with massive cell loss; Jongen-Relo and Feldon, 2002; Figure 4E) and behavioral criteria. The latter consisted in the evaluation of the attraction to a specific male odor source after repeated VN contact (a function which relies on the integrity of this nucleus; Moncho-Bogani et al., 2005). Adult (p45), but not pre-pubertal (p20), female mice were attracted by male volatile odors after physical contact with male non-volatile compounds (p45: experienced, $0.64 \pm 0.03 \mathrm{pT}$; unexperienced, $0.36 \pm 0.03 \mathrm{pT} ; \quad U=0.001 ; \mathrm{p} 20$ : experienced, $0.47 \pm 0.03$ pT; unexperienced, $0.52 \pm 0.03$ pT; $U=0.327 ; n=18$ for $\mathrm{p} 20, n=25$ for $\mathrm{p} 45$; means $\pm \mathrm{SEM})$. Such behavioral response was accompanied by concurrent neuronal activation of the medial amygdala (p45, experienced, $43 \pm 1.5$ nuclei/area, unexperienced, $60 \pm 5.5$ nuclei/area; $P=0.0409$; means $\pm \mathrm{SEM}$ ). Importantly, MeA-lesioned, but not sham-lesioned (saline injected) mice, failed to show an attractive response to male odors (IB: experienced, $0.387 \pm 0.06 \mathrm{pT}$, unexperienced, $0.612 \pm 0.06 \mathrm{pT}, U=0.172$; saline: experienced, $0.632 \pm 0.03 \mathrm{pT}$, naïve, $0.367 \pm 0.03 \mathrm{pT}$; $U=0.006$; means $\pm \mathrm{SEM}$ ), thus confirming the effectiveness of the lesion.

We also found that sham-lesioned mice showed an increase in cell survival in the AOB-GrL after exposure to male soiled bedding whereas IB-treated mice did not (Figure 4F). By contrast, granule cell survival in the MOB was unaffected by either bedding exposure or IB lesioning (Figure 4G). Together, our results indicate that positive selection of new AOB granule cells depends on both centripetal as well as centrifugal sensory activity. These findings are reminiscent of recent experiments in the MOB (Petreanu and Alvarez-Buylla, 2002; Yamaguchi and Mori, 2005; Whitman and Greer, 2007; Panzanelli et al., 2009; Veyrac et al., 2009).

\section{AOB NEUROGENESIS IS NECESSARY TO PREVENT MATE INDUCED PREGNANCY BLOCK}

To confirm the involvement of newborn AOB granule cells in mate memory formation, we blocked the renewal of adultborn interneurons by infusing the anti-mitotic drug Ara-C using osmotic mini-pumps (Breton-Provencher et al., 2009). Although alternative methods are available to block the genesis of new neurons in the brain (e.g., X-ray exposure or gene-coded selective deletion; Lazarini et al., 2009; Lazarini and Lledo, 2011), we favored Ara-C brain infusion because it is the most efficient way to eliminate the production of SVZ newborn cells even after shortterm treatment (Doetsch et al., 1999; Breton-Provencher et al., 2009) and low doses of Ara-C that we and others used have no aversive side-effects (Moreno et al., 2009; Lazarini and Lledo, 2011). By contrast, X-ray irradiation only partially reduces SVZ neurogenesis (Lazarini et al., 2009) and genetic ablation of neurogenesis often requires injection of tamoxifen (Imayoshi et al., 2008; Sakamoto et al., 2011), a substance which is a potential source of bias when studying sexually dimorphic and estrogen responsive structures such as the vomeronasal system (Halbreich and Kahn, 2000; Hoffmann and Schuler, 2000; Kedia-Mokashi et al., 2011).

Infusion of Ara-C for 28 days following previously established protocols (Breton-Provencher et al., 2009) completely eliminated from the AOB the cells that we found to be preferentially activated by male odors (Figure 1G; Figure 5A). BrdU injections were 

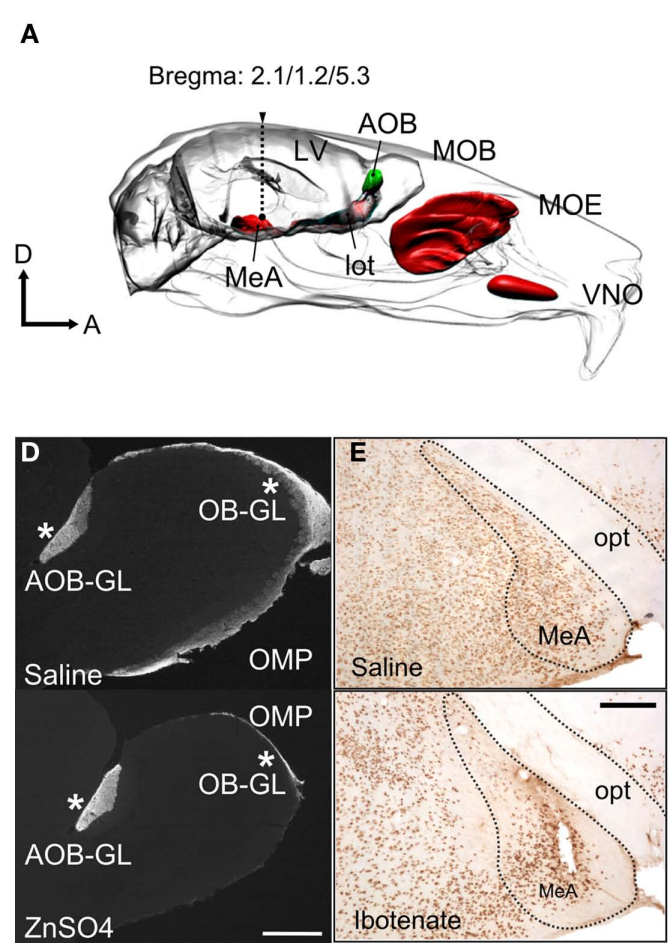

FIGURE 4 | Survival of new AOB granule cells depends on amygdala feedback activity induced by vomeronasal input. (A) Sites of functional impairment in the vomeronasal system: MeA, medial amygdala; MOE, main olfactory epithelium; VNO, vomeronasal organ (lot, lateral olfactory tract; LV, lateral ventricle). (B,C) Newborn 4-weeks-old $\mathrm{AOB}$ granule cells in trpc2 $+/+$ trpc $2^{--}$(B) and $\mathrm{ZnSO}_{4}$ (C) mice exposed to male bedding 1 week after BrdU injection. (D) Micrographs showing the loss of OMP expression in the MOB of $\mathrm{ZnSO}_{4}$-treated mice (lower), compared to saline-treated animals (upper). In both cases OMP labeling is present in the AOB glomerular layer (asterisks at the right) but absent in the $\mathrm{MOB}$ of the $\mathrm{ZnSO}_{4}$-treated mice (asterisk on the
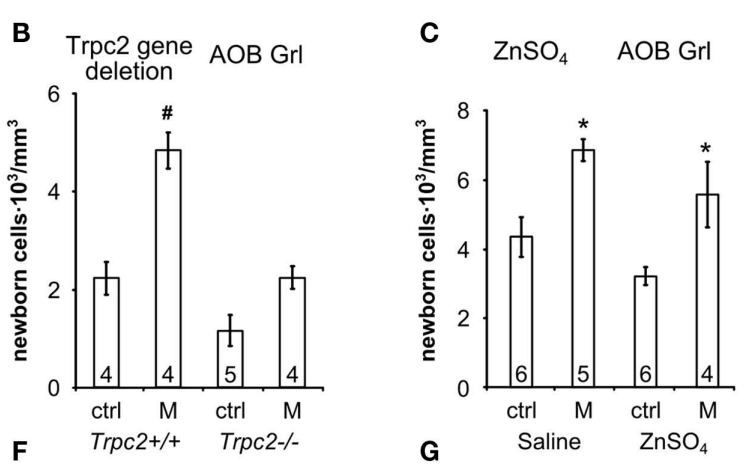

MeA-X (IB) AOB Grl

MeA-X (IB) MOB Grl
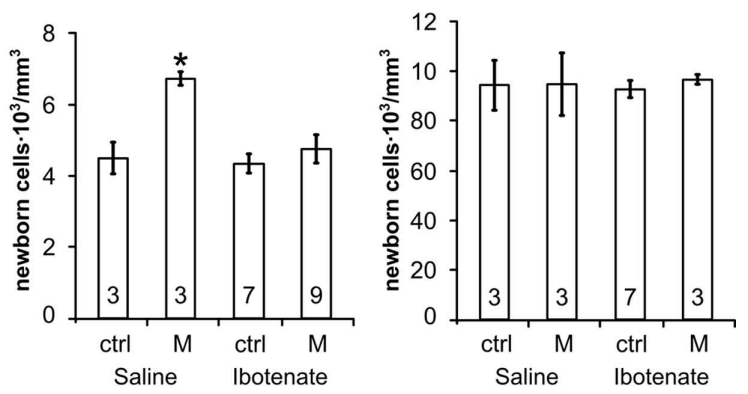

left). This indicates that the lesion has left the VNO undamaged. (E) Pictures showing NeuN labeling in the medial amygdala (MeA) after saline and ibotenate injections, respectively. The loss of labeled neuronal nuclei reveals the extent of neuronal death induced by the lesion after injection of ibotenate (opt: optic tract). (F,G) BrdU-positive cell density in the AOB (F) and MOB GrL (G) evaluated 1 month after injection, in ibotenate-treated (IB) and saline-treated females. The line in the dot plots is the sample median, other data are means \pm SEM, the numbers in the graph bars indicate the amount of animals used. Bars: in (D), $200 \mu \mathrm{m}$; in (E), $100 \mu \mathrm{m} .{ }^{*} P<0.05$, ${ }^{\#} P<0.001$. performed at the 14th day of the anti-mitotic treatment and the efficiency of neurogenesis ablation was assessed at the 28th day.

Female mice treated with Ara-C completely lacked BrdU and DCX labeling (Figure 5A), while saline-treated females showed a normal rate of neurogenesis in the OB. Notably, the amount of pre-existing neurons (NeuN-positive) remained unchanged in the $\mathrm{AOB}$ after Ara-C infusion (Figures 5B,C), indicating that the treatment specifically affected newly generated cells.

Next, after a 4-week-long ablation of bulbar neurogenesis, we tested Ara-C treated females for their ability to recognize the mate and thus avoid pregnancy block by male odor stimuli. Briefly, female mice were mated and subsequently re-exposed to the familiar partner odor during the following 3 days (Figure 6A; Bruce, 1966; Peele et al., 2003; Leinders-Zufall et al., 2004). Under control conditions (saline-treated female mice) re-exposure to the familiar mate odor did not induce pregnancy block, as indicated by a high pregnancy rate (or low pregnancy failure rate; Figure 6A, experiment 1 ). In stark contrast, females treated with Ara-C for 4-weeks underwent pregnancy block when re-exposed to the mate (Figures 6A,B, experiment 2), indicating that in absence of younger neurons they fail to imprint on the odors of the mating partner, as they are treated as unfamiliar ones.
However, the high pregnancy failure rate observed after neurogenesis ablation could be a result of Ara-C induced infertility. To rule out this possibility, we quantified the pregnancy rate after Ara- $\mathrm{C}$ treatment without subsequent exposure to the mating partner (Figure 6A, experiment 3). In this case, the pregnancy rate remained high and comparable to controls, indicating that the high pregnancy failure observed in experiment 2 was specifically induced by odor exposure after mating.

As a further control, we analyzed the effect of short-term Ara- $\mathrm{C}$ treatment on mate recognition efficiency (the same dose of the whole long-term treatment was given; Figure 6A, experiment 4) by starting the brain infusion 1 week before mating only. Under this condition, re-exposure to familiar odor did not induce pregnancy block. Hence, when compared with the findings of experiment 2, the inability of the short-term Ara-C treatment to induce pregnancy block (experiment 4) confirms that the lack of neurons aged between 2 and 4 weeks is ultimately responsible for switching the outcome of the pregnancy block test.

Finally, since Ara-C treatment eliminates newborn cells also in the MOB and the impact of this ablation on mate recognition is unknown, we tested the effects of mate re-exposure 

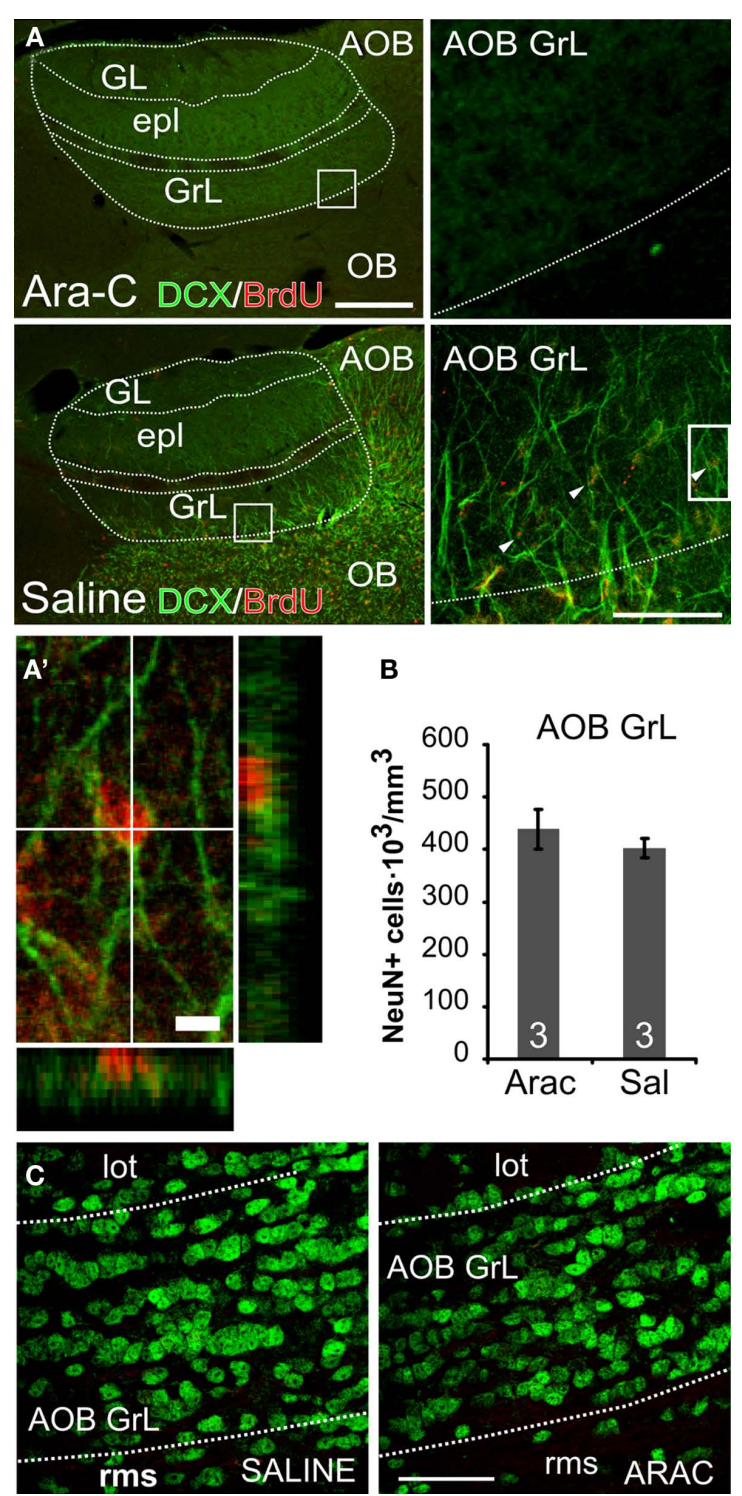

B
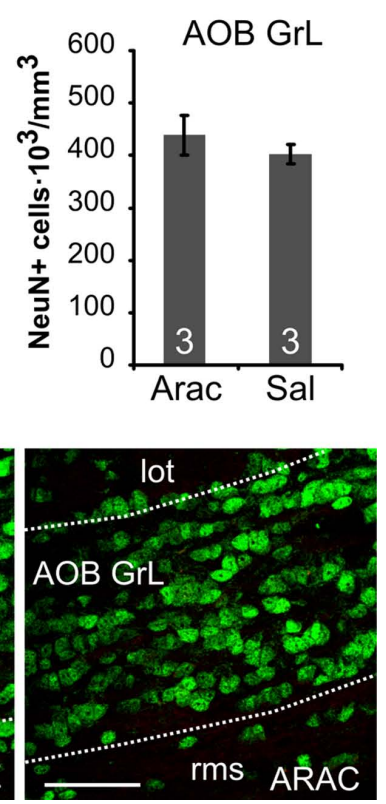

FIGURE 5 | Newborn but not pre-existing AOB-GrL interneurons are eliminated by Ara-C treatment. (A) Micrographs showing double immunolabeling for doublecortin (DCX) and BrdU performed at the end of a saline or Ara-C (28 days) infusion. Mice infused with Ara-C (upper panels) show a complete loss of immature neurons ( $D C X+$, green staining) and newborn ones (BrdU+ in red) contrarily to saline-treated animals [lower panels; newborn cells are indicated with arrowheads in the higher magnification panel on the right and in $\left.\left(\mathbf{A}^{\prime}\right) ; x: y: z=1: 1: 4\right]$. (B), NeuN+ cell density quantification in the granular layer of the $A O B$ of saline and Ara-C treated mice. Data are means \pm SEM ( $n=3$ animals per group). (C) micrographs showing NeuN labeling in the AOB-GrL of Ara-C and saline-treated mice (lot, lateral olfactory tract; GrL, granular layer; rms, rostral migratory stream). Bars in (A): left $200 \mu \mathrm{m}$, middle $50 \mu \mathrm{m}, 5 \mu \mathrm{m}$ for the single cell magnification. In (C): $50 \mu \mathrm{m}$. Means \pm SEM, the numbers in the graph bars indicate the amount of animals used.

on Ara-C treated females subjected to surgical lesion of the vomeronasal nerves (VNX), a condition that alone is reported to eliminate exteroceptive pregnancy block (Figure 6A, experiments
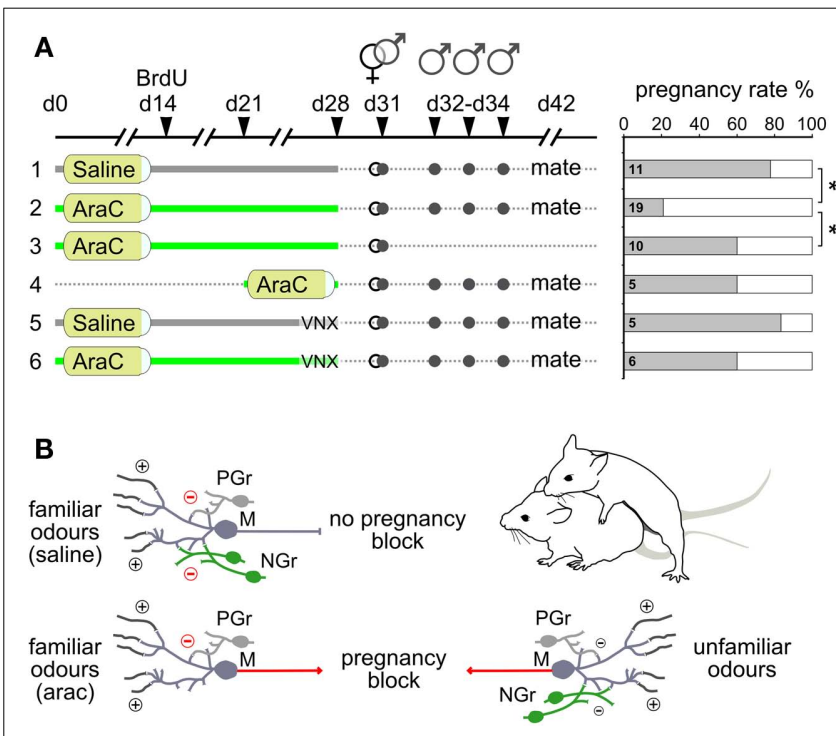

FIGURE 6 | Newborn granule cells in the AOB are necessary for mating partner recognition. (A) Matings and male stimulations on female mice after different protocols of Ara-C/saline treatment in normal and vomeronasal nerve-lesioned mice (VNX). Shown in the graph are the pregnancy rates (in percentage) as a function of the different treatment conditions evaluated 11 days after mating. (B) Schematic diagram illustrating the role of $\mathrm{AOB}$ newborn granule cells ( $\mathrm{NGr}$ ) in the modulation of mate's familiar signals (left side) and unfamiliar ones (right side): granule cells are preferentially involved in the detection of male individual odors once integrated into pre-existing circuits. When highly responsive newborn granule cells (NGr) are eliminated after Ara-C treatment (left side, bottom), pre-existing granule cells (PGr) are not sufficient to prevent pregnancy block by mate's familiar odors (red arrows). ${ }^{*} P<0.05$, (Table 1 ).

5, 6; Figure 7A; Bellringer et al., 1980; Matsuoka et al., 2005). Consistent with a lack of $\mathrm{MOB}$ involvement in this recognition process, after blockade of neurogenesis (Ara- $\mathrm{C}$ treatment) in VNX mice, stud male odors where not effective in halting pregnancy onset after mating. Thus, in the absence of VN inputs, a lack of $\mathrm{MOB}$ newborn granule cells does not lead to pregnancy block by familiar pheromonal signals indicating that newborn cells in the $\mathrm{MOB}$ are not required for this imprinting process. As a further control that Ara-C treatment does not disrupt the ability to discriminate male volatile odors, we performed a habituation-dishabituation assay - which allows for measurement of MOE-dependent novel odor investigation, short-term odor learning, and odor discrimination - but found no significant difference (hab4 vs. dishab, $t$-test, $P<0.05$ for Ara-C, Saline, and Saline-VNX mice) between sham-lesioned and Ara-C treated VNX female mice (Figure 7B). Together, these results indicate that the lack of bulbar newborn neurons compromises primarily AOB-mediated discrimination, as shown by the mate recognition impairment.

\section{DISCUSSION}

Our results highlight a direct link between VN sensory inputs and $\mathrm{AOB}$ neurogenesis, and a crucial role for $\mathrm{AOB}$ newborn neurons as preferential cellular substrate for mate pheromonal imprinting in adult female mice. Neurogenesis in the OB received considerable 

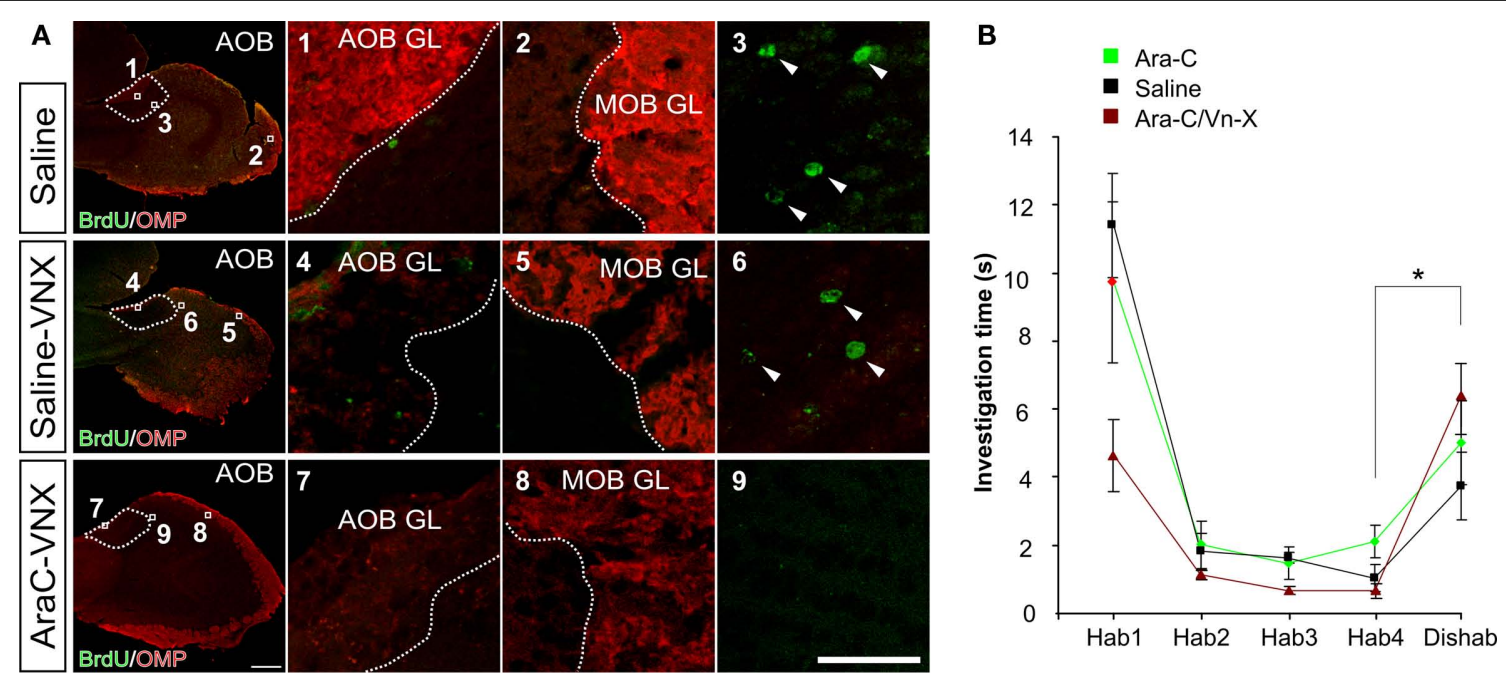

FIGURE 7 | Infusion of anti-mitotic drug Ara-C eliminates olfactory bulb neurogenesis but does not impair male odor recognition. (A) Immunostaining for OMP and BrdU in the OB after Saline/Ara-C treatment and surgical lesion of the vomeronasal nerve (experiments 1, 5, and 6 in Figure 6). The injections of BrdU have been performed 14 days after the beginning of brain infusion. In the third row, the lack of OMP/BrdU double immunoreactivity shows the efficiency of VN surgery and neurogenesis ablation in Ara-CNNX mice compared to saline-treated mice (controls and $\mathrm{VN}$-lesioned mice). Bars in (A), $500 \mu \mathrm{m}$ for low magnification images, $40 \mu \mathrm{m}$ for image details. (B) Habituation/dishabituation task for male volatile odor discrimination in Saline/Ara-C treated mice. Odor sources consisted of filter paper stripes soaked with male urine derived from different individuals and contained in a plastic box to prevent direct nasal contact but not odor perception. Mice were habituated to an odor with four consecutive presentations. On the fifth presentation a different odor was presented. Both saline-treated and neurogenesis-ablated mice (normal or VNX) similarly increased the investigation time in response to the new odor. Means $\pm S E M$, ${ }^{*} P<0.05$. attention in the last decade, due to the suitability of the SVZ-OB model to study the functional implication of neurons generated during adulthood in sensory processes. Surprisingly, few authors considered explicitly in their analyses this unceasing cell renewal in the AOB (Bayer, 1983; Bonfanti et al., 1997; Peretto et al., 1999; Martinez-Marcos et al., 2001; Sakamoto et al., 2011; Veyrac and Bakker, 2011). Furthermore, the functional role of newborn neurons in the perception of social odors and pheromones has been evaluated only in the MOB (Shingo et al., 2003; Mak et al., 2007; Larsen et al., 2008; Feierstein et al., 2010; Mak and Weiss, 2010) with the exception of a few reports considering both the AOB and the MOB (Oboti et al., 2009; Nunez-Parra et al., 2011; Sakamoto et al., 2011). Therefore, to our knowledge, an integrated study focused both at a cellular and behavioral level on the VNS circuitry, is still lacking. Moreover, a possible involvement of AOB neuronal turn-over in the well known granule-to-mitral AOB synaptic plasticity occurring during mating, which is the neural correlate of mate recognition (Brennan and Keverne, 1997; Matsuoka et al., 2004), remained untested.

Here we have hypothesized that this memory formation process, established in a short time window during mating, could be promoted by the presence of renewed interneurons in the AOB of adult female mice.

Accordingly, we report firstly that in adult female mice the functional integration of these cells is triggered by the exposure to male odors: such sensory-driven positive selection acted preferentially on 2-3 weeks old granule cells (Figure 1A). In addition, shortly after their integration, these neurons became particularly responsive toward the experienced sensory stimuli (as shown by BrdU and c-Fos imaging, Figure 1G). Thus, the timing of this process is coherent with a rapid involvement of these interneurons in $\mathrm{AOB}$ circuits underlying individual recognition.

Moreover, the same sensory activity increased the survival of 3 weeks old MOB granule cell but their preferential involvement in OB sensory processing occurred only around the 6th week of age. Therefore, it is likely that only young AOB granule cells are selectively and rapidly involved in the elaboration of male individual chemosensory signals.

More generally, such neuronal selectivity and perceptual resolution of peripheral sensory areas is modified through sensory experience via feedback connections between higher and lower cortical levels (Gilbert and Sigman, 2007). Thus, we argued that if $\mathrm{VN}$ sensory inputs and $\mathrm{AOB}$ neurogenesis would have been similarly linked, the hypothesis of the functional involvement of AOB newborn cells in male odor recognition would have gained likelihood.

Concerning the sensory structures involved in this olfactory task, it is known that the main and accessory olfactory pathways act synergistically in pheromonal odor processing through convergent projections to the medial amygdaloid region (MeA; Moncho-Bogani et al., 2005). From here, a feedback loop is formed by excitatory centrifugal afferents contacting the AOB granular layer which, in turn, directly regulates the local activity in response to external stimuli (Pankevich et al., 2006; Fan and Luo, 2009; Martel and Baum, 2009). Hence, AOB neuronal activity, and neurogenesis as well, can be alternatively modulated by either direct peripheral sensory stimulation through VNO-MeA activation, or indirectly by MOE-MeA centrifugal inputs. 
Thereafter, by selective functional ablation of the main sensory relays involved in social odor perception (MOE, VNO, MeA), we reported that the neurogenic process observed in the $\mathrm{AOB}$ is actively guided by VNO-MeA sensory activity (but not MOE$\mathrm{MeA}$ ) underlying its substantial correlation with vomeronasal sensory processing.

Sustained by these evidences, we have halted the production of new neurons in the brain by intracerebroventricular (ICV) Ara-C infusion and tested the ability of adult female mice to recognize their mating partners in order to avoid exteroceptive implantation failure. The drug infusion period covered the time window for AOB granule cell peak responsiveness to male individual odors.

As a result of the neurogenesis blockade, we found a high rate of pregnancy failure in recently mated females after exposure to the mating partner. This effect was specifically due to the re-exposure to the stud male since no such pregnancy failure did follow when Ara- $\mathrm{C}$ was given alone. Although Ara-C treated female mice showed a subtle decrease in pregnancy rates in comparison to saline-treated females (Figure 6A, experiments 3, 4 vs. 1; 60 vs. $77 \%=17 \%)$, the strong decrease in pregnancy rate evident after re-exposure to the mating male goes far beyond these differences (Figure 6A; 2 vs. 3, $4 ; 21$ vs. $60 \%=39 \%$ ). Nevertheless, this pregnancy failure rate does not reach the levels observed in our control conditions and in other reports (60-70\%; Bruce, 1966; Brennan and Zufall, 2006), possibly because older cells (aged over 28 days) spared by the anti-mitotic treatment could constitute a residual substrate for the imprinting process.

Notably, the memory established on the stud male urine odors during mating is localized specifically at the granule-to-mitral synaptic interface in the AOB (Kaba et al., 1989). Thus, our results strongly support a preferential role of $\mathrm{AOB}$ newly generated neurons in this olfactory recognition process (Figure 6B), despite a capability of the main olfactory system to detect mate's pheromones (Brennan and Zufall, 2006) and widespread antineurogenic CNS effects following Ara-C ICV infusion. In addition, a lack of involvement of MOB interneurons was further supported by the fact that the 4 -week long anti-mitotic treatment left undamaged those new granule cells (6 weeks old) highly responding to male familiar cues in this region (Figure 1H). Although this

\section{REFERENCES}

Alvarez-Buylla, A., and Garcia-Verdugo, J. M. (2002). Neurogenesis in adult subventricular zone. J. Neurosci. 22, 629-634.

Bayer, S. A. (1983). 3H-thymidineradiographic studies of neurogenesis in the rat olfactory bulb. Exp. Brain Res. 50, 329-340.

Bellringer, J. F., Pratt, H. P., and Keverne, E. B. (1980). Involvement of the vomeronasal organ and prolactin in pheromonal induction of delayed implantation in mice. J. Reprod. Fertil. 59, 223-228.

Bonfanti, L., Peretto, P., Merighi, A., and Fasolo, A. (1997). Newly-generated cells from the rostral migratory stream in the accessory olfactory

observation alone does not rule out the involvement of these neurons in mate recognition, a role of the MOB in the avoidance of pregnancy block was shown only 6.5 days after mating (Serguera et al., 2008) and therefore is not compatible with our mate exposition protocol. Eventually, female mice treated with Ara- $\mathrm{C}$ were still able to discriminate male individual odors, thus implying the lack of cells aged up to 4 weeks does not disturb normal olfactory recognition of individual males. Nevertheless, to confirm this idea and test the effect of neurogenesis ablation only in the MOB, we have blocked vomeronasal inputs by lesioning the vomeronasal nerves in Ara-C treated female mice. This procedure was sufficient to prevent the high rate of pregnancy block by stud male exposure, ruling out the involvement of $\mathrm{MOB}$ newborn interneurons (aged 1-4 weeks) in mate recognition and confirming the key role of AOB interneurons in this process (Kaba et al., 1989; Hudson, 1993).

In conclusion our experiments demonstrate the importance of newly generated $\mathrm{AOB}$ inhibitory interneurons in the mating pheromonal imprinting process. Therefore, we provide evidence that neurogenesis in the adult brain is indeed of extraordinary functional significance, playing a critical role in the context of AOB-mediated sensory processing, persistent odor learning, and mate recognition. Our results also imply that newborn $\mathrm{AOB}$ interneurons are necessary to convey nerve signals that, ultimately, lead to determined neuroendocrine responses in higher circuits of the vomeronasal pathway. The survival of new neurons in the AOB seems to be regulated by both the detection of species-specific, sensory vomeronasal stimuli, included in the LMW urine fraction, that requires an intact $\operatorname{Trpc} 2$ cation channel, and central inputs from the medial amygdala. The identification of the function of newly generated $\mathrm{AOB}$ interneurons in pheromonal mate recognition provides an attractive cellular substrate to begin to dissect the molecular logic of this feat.

\section{ACKNOWLEDGMENTS}

This work has been supported by Compagnia di San Paolo (2008.2192), Turin, Italy, PRIN 2007, the Deutsche Forschungsgemeinschaft (Pablo Chamero, Frank Zufall, and Trese LeindersZufall) and the Volkswagen Foundation (Trese Leinders-Zufall).

olfactory behaviors. J. Neurosci. 29, 15245-15257.

81, 489-502.

Brennan, P., Kaba, H., and Keverne, E. B. (1990). Olfactory recognition: a simple memory system. Science 250, 1223-1226.

Brennan, P. A., and Keverne, E. B. (1997). Neural mechanisms of mammalian olfactory learning. Prog. Neurobiol. 51, 457-481.

Brennan, P. A., and Zufall, F. (2006). Pheromonal communication in vertebrates. Nature 444, 308-315.

Breton-Provencher, V., Lemasson, M., Peralta, M. R. III, and Saghatelyan, A. (2009). Interneurons produced in adulthood are required for the normal functioning of the olfactory bulb network and for the execution of selected
Bruce, H. M. (1966). Smell as an exteroceptive factor. J. Anim. Sci. 25, 83-87.

Chamero, P., Marton, T. F., Logan, D. W., Flanagan, K., Cruz, J. R., Saghatelian, A., Cravatt, B. F., and Stowers, L. (2007). Identification of protein pheromones that promote aggressive behaviour. Nature 450, 899-902.

Chauveau, F., Pierard, C., Coutan, M., Drouet, I., Liscia, P., and Béreatex or basolateral amygdala lesions blocked the stress-induced inversion of serial memory retrieval pattern in mice. Neurobiol. Learn. Mem. 90, 395-403. cochéa, D. (2008). Prefrontal cor-
Doetsch, F., Garcia-Verdugo, J. M., and Alvarez-Buylla, A. (1999). Regeneration of a germinal layer in the adult mammalian brain. Proc. Natl. Acad. Sci. U.S.A. 96, 11619-11624.

Fan, S., and Luo, M. (2009). The organization of feedback projections in a pathway important for processing pheromonal signals. Neuroscience 2, 489-500.

Feierstein, C. E., Lazarini, F., Wagner, S., Gabellec, M. M., de Chaumont, F., Olivo-Marin, J. C., Boussin, F. D., Lledo, P. M., and Gheusi, G. (2010). Disruption of adult neurogenesis in the olfactory bulb affects social interaction but not maternal behavior. Front. Behav. Neurosci. 4:176. doi: 10.3389/fnbeh.2010.00176 
Gheusi, G., Ortega-Perez, I., Murray, K., and Lledo, P. M. (2009). A niche for adult neurogenesis in social behavior. Behav. Brain Res. 200, 315-322.

Gilbert, C. D., and Sigman, M. (2007). Brain states: top-down influences in sensory processing. Neuron 5, 677-696.

Halbreich, U., and Kahn, L. S. (2000). Selective oestrogen receptor modulators - current and future brain and behaviour applications. Expert Opin. Pharmacother. 1, 1385-1398.

Halem, H. A., Cherry, J. A., and Baum, M. J. (2001). Central forebrain Fos responses to familiar male odours are attenuated in recently mated female mice. Eur. J. Neurosci. 13, 389-399.

Hoffmann, B., and Schuler, G. (2000). Receptor blockers - general aspects with respect to their use in domestic animal reproduction. Anim. Reprod. Sci. 60-61; 295-312.

Hosokawa, N., and Chiba, A. (2007). Effects of sexual experience on conspecific odor preference and male odor-induced activation of the vomeronasal projection pathway and the nucleus accumbens in female rats. Brain Res. 1175, 66-75.

Hudson, R. (1993). Olfactory imprinting. Curr. Opin. Neurobiol. 3, 548-552.

Imayoshi, I., Sakamoto, M., Ohtsuka, T., Takao, K., Miyakawa, T., Yamaguchi, M., Mori, K., Ikeda, T., Itohara, S., and Kageyama, R. (2008). Roles of continuous neurogenesis in the structural and functional integrity of the adult forebrain. Nat. Neurosci. 11, 1153-1161.

Jongen-Relo, A. L., and Feldon, J. (2002). Specific neuronal protein: a new tool for histological evaluation of excitotoxic lesions. Physiol. Behav. 76, 449-456.

Kaba, H., Rosser, A., and Keverne, B. (1989). Neural basis of olfactory memory in the context of pregnancy block. Neuroscience 32, 657-662.

Kedia-Mokashi, N. A., Mugasimangalam, R., Aiyaz, M., Mukherjee, S., and Balasinor, N. H. (2011). Aberrant expression of imprinted genes in post-implantation rat embryos. Life Sci. 88, 634-643.

Kee, N., Teixeira, C. M., Wang, A. H., and Frankland, P. W. (2007). Preferential incorporation of adultgenerated granule cells into spatial memory networks in the dentate gyrus. Nat. Neurosci. 10, 355-362.

Kovacs, K. J. (2008). Measurement of immediate-early gene activation- cfos and beyond. J. Neuroendocrinol. 20, 665-672.
Larsen, C. M., Kokay, I. C., and Grattan, D. R. (2008). Male pheromones initiate prolactin-induced neurogenesis and advance maternal behavior in female mice. Horm. Behav. 53, 509-517.

Lazarini, F., and Lledo, P. M. (2011). Is adult neurogenesis essential for olfaction? Trends Neurosci. 34, 20-30.

Lazarini, F., Mouthon, M. A., Gheusi, G., de Chaumont, F., Olivo-Marin, J. C., Lamarque, S., Abrous, D. N., Boussin, F. D., and Lledo, P. M. (2009). Cellular and behavioral effects of cranial irradiation of the subventricular zone in adult mice. PLoS ONE 4, e7017. doi: 10.1371/journal.pone.0007017

Leinders-Zufall, T., Brennan, P., Widmayer, P., Chandramani, P. S., MaulPavicic, A., Jäger, M., Li, X. H., Breer, H., Zufall, F., and Boehm, T. (2004). MHC class I peptides as chemosensory signals in the vomeronasal organ. Science 306, 1033-1037.

Leypold, B. G., Yu, C. R., LeindersZufall, T., Kim, M. M., Zufall, F., and Axel, R. (2002). Altered sexual and social behaviors in trp2 mutant mice. Proc. Natl. Acad. Sci. U.S.A. 99, 6376-6381.

Li, C. S., Kaba, H., Saito, H., and Seto, K. (1989). Excitatory influence of the accessory olfactory bulb on tuberoinfundibular arcuate neurons of female mice and its modulation by oestrogen. Neuroscience 29, 201-208.

Lin, C. W., Sim, S., Ainsworth, A., Okada, M., Kelsch, W., and Lois, C. (2010). Genetically increased cellintrinsic excitability enhances neuronal integration into adult brain circuits. Neuron 1, 32-39.

Magavi, S. S., Mitchell, B. D., Szentirmai, O., Carter, B. S., and Macklis, J. D. (2005). Adult-born and preexisting olfactory granule neurons undergo distinct experience-dependent modifications of their olfactory responses in vivo. J. Neurosci. 25, 10729-10739.

Mak, G. K., Enwere, E. K., Gregg, C., Pakarainen, T., Poutanen, M., Huhtaniemi, I., and Weiss, S. (2007) Male pheromone-stimulated neurogenesis in the adult female brain: possible role in mating behavior. Nat. Neurosci. 10, 1003-1011.

Mak, G. K., and Weiss, S. (2010). Paternal recognition of adult offspring mediated by newly generated CNS neurons. Nat. Neurosci. 13, 753-758.

Martel, K. L., and Baum, M. J. (2009). A centrifugal pathway to the mouse accessory olfactory bulb from the medial amygdala conveys genderspecific volatile pheromonal signals. Eur. J. Neurosci. 29, 368-376.
Martinez-Marcos, A., Ubeda-Banon, I., and Halpern, M. (2001). Cell migration to the anterior and posterior divisions of the granule cell layer of the accessory olfactory bulb of adult opossums. Brain Res. Dev. Brain Res. 127, 95-98.

Matsuoka, M., Kaba, H., Mori, Y., and Ichikawa, M. (1997). Synaptic plasticity in olfactory memory formation in female mice. Neuroreport 8, 2501-2504.

Matsuoka, M., Kaba, H., Moriya, K., Yoshida-Matsuoka, J., Costanzo, R. M., Norita, M., and Ichikawa, M. (2004). Remodeling of reciprocal synapses associated with persistence of long-term memory. Eur. J. Neurosci. 19, 1668-1672.

Matsuoka, M., Norita, M., and Costanzo, R. M. (2005). A new surgical approach to the study of vomeronasal system regeneration. Chem. Senses 30(Suppl. 1), i129-i130.

McBride, K., Slotnick, B., and Margolis, F. L. (2003). Does intranasal application of zinc sulfate produce anosmia in the mouse? An olfactometric and anatomical study. Chem. Senses 28 , 659-670.

Moncho-Bogani, J., Martinez-Garcia, F., Novejarque, A., and Lanuza, E. (2005). Attraction to sexual pheromones and associated odorants in female mice involves activation of the reward system and basolateral amygdala. Eur. J. Neurosci. 21, 2186-2198.

Moreno, M. M., Linster, C., Escanilla, O., Sacquet, J., Didier, A., and Mandairon, N. (2009). Olfactory perceptual learning requires adult neurogenesis. Proc. Natl. Acad. Sci. U.S.A. 106, 17980-17985.

Morgan, J. I., Cohen, D. R., Hempstead, J. L., and Curran, T. (1987). Mapping patterns of c-Fos expression in the central-nervous-system after seizure. Science 237, 192-197.

Nunez-Parra, A., Pugh, V., and Araneda, R. C. (2011). Regulation of adult neurogenesis by behavior and age in the accessory olfactory bulb. Mol. Cell. Neurosci. 4, 274-285.

Oboti, L., Savalli, G., Giachino, C., De Marchis, S., Panzica, G. C., Fasolo, A., and Peretto, P. (2009). Integration and sensory experience-dependent survival of newly-generated neurons in the accessory olfactory bulb of female mice. Eur. J. Neurosci. 29, 679-692.

Pankevich, D. E., Cherry, J. A., and Baum, M. J. (2006). Accessory olfactory neural Fos responses to a conditioned environment are blocked in male mice by vomeronasal organ removal. Physiol. Behav. 87, 781-788.

Panzanelli, P., Bardy, C., Nissant, A., Pallotto, M., Sassoe-Pognetto, M., Lledo, P. M., and Fritschy, J. M. (2009). Early synapse formation in developing interneurons of the adult olfactory bulb. J. Neurosci. 29, 15039-15052.

Peele, P., Salazar, I., Mimmack, M., Keverne, E. B., and Brennan, P. A. (2003). Low molecular weight constituents of male mouse urine mediate the pregnancy block effect and convey information about the identity of the mating male. Eur. J. Neurosci. 18, 622-628.

Peretto, P., Merighi, A., Fasolo, A., and Bonfanti, L. (1999). The subependymal layer in rodents: a site of structural plasticity and cell migration in the adult mammalian brain. Brain Res. Bull. 49, 221-243.

Petreanu, L., and Alvarez-Buylla, A. (2002). Maturation and death of adult-born olfactory bulb granule neurons: role of olfaction. J. Neurosci. 22, 6106-6113.

Sakamoto, M., Imayoshi, I., Ohtsuka, T., Yamaguchi, M., Mori, K., and Kageyama, R. (2011). Continuous neurogenesis in the adult forebrain is required for innate olfactory responses. Proc. Natl. Acad. Sci. U.S.A. 20, 8479-8484.

Serguera, C., Triaca, V., Kelly-Barrett, J., Banchaabouchi, M. A., and Minichiello, L. (2008). Increased dopamine after mating impairs olfaction and prevents odor interference with pregnancy. Nat. Neurosci. 11, 949-956.

Shingo, T., Gregg, C., Enwere, E., Fujikawa, H., Hassam, R., Geary, C., Cross, J. C., and Weiss, S. (2003). Pregnancy-stimulated neurogenesis in the adult female forebrain mediated by prolactin. Science 299, 117-120.

Veyrac, A., and Bakker, J. (2011). Postnatal and adult exposure to estradiol differentially influences adult neurogenesis in the main and accessory olfactory bulb of female mice. FASEB J. 25, 1048-1057.

Veyrac, A., Sacquet, J., Nguyen, V., Marien, M., Jourdan, F., and Didier, A. (2009). Novelty determines the effects of olfactory enrichment on memory and neurogenesis through noradrenergic mechanisms. $\mathrm{Neu}$ ropsychopharmacology 34, 786-795.

Whitman, M. C., and Greer, C. A. (2007). Synaptic integration of adult-generated olfactory bulb granule cells: basal axodendritic centrifugal input precedes apical dendrodendritic local circuits. J. Neurosci. 27, 9951-9961. 
Xia, J., Sellers, L. A., Oxley, D., Smith, T., Emson, P., and Keverne, E. B. (2006). Urinary pheromones promote ERK/Akt phosphorylation, regeneration and survival of vomeronasal (V2R) neurons. Eur. J. Neurosci. 24, 3333-3342.

Xu, F., Schaefer, M., Kida, I., Schafer, J., Liu, N., Rothman, D. L., Hyder, F., Restrepo, D., and Shepherd, G. M. (2005). Simultaneous activation of mouse main and accessory olfactory bulbs by odors or pheromones. J. Comp. Neurol. 489, 491-500.

Yamaguchi, M., and Mori, K. (2005).

Critical period for sensory experience-dependent survival of newly generated granule cells in the adult mouse olfactory bulb. Proc. Natl. Acad. Sci. U.S.A. 102, 9697-9702.

Conflict of Interest Statement: The authors declare that the research was conducted in the absence of any commercial or financial relationships that could be construed as a potential conflict of interest.

Received: 08 July 2011; paper pending published: 06 August 2011; accepted: 05 September 2011; published online: 28 September 2011.

Citation: Oboti L, Schellino R, Giachino C, Chamero P, Pyrski M, Leinders-Zufall T, Zufall F, Fasolo A and Peretto P (2011) Newborn interneurons in the accessory olfactory bulb promote mate recognition in female mice. Front. Neurosci. 5:113. doi: 10.3389/fnins.2011.00113
This article was submitted to Frontiers in Neurogenesis, a specialty of Frontiers in Neuroscience.

Copyright (C) 2011 Oboti, Schellino, Giachino, Chamero, Pyrski, LeindersZufall, Zufall, Fasolo and Peretto. This is an open-access article subject to a nonexclusive license between the authors and Frontiers Media SA, which permits use, distribution and reproduction in other forums, provided the original authors and source are credited and other Frontiers conditions are complied with. 